\title{
AN ANALYSIS OF THE CENTRALITY OF INTUITION TALK IN THE DISCUSSION ON TASTE DISAGREEMENTS**
}

\begin{abstract}
According to Cappelen (2012), analytic philosophers have traditionally used two arguments to defend the role of intuitions in philosophy. On the one hand, The Argument from Philosophical Practice claims that analytic philosophers rely on intuitions when defending their theories. On the other hand, The Argument from Intuition Talk contends that intuitions must play a prominent role in analytic philosophy because analytic philosophers use intuition talk profusely. Cappelen (2012) identifies three questions to be considered when assessing the Argument from Intuition Talk: a quantitative question, a centrality question, and an interpretative question. The available studies have mainly focused on the quantitative and interpretative questions. In this paper, I examine the centrality question, taking as a case study the literature on taste disagreements a topic that has received significant attention in the philosophy of language in the last fifteen years. To this end, I first build a corpus with the most relevant works in the area and then examine the centrality of intuition talk. The results show that the use of intuition talk is central in the literature on taste disagreements, and that intuitions are taken as evidence in favor of a given theory if the theory can account for them.
\end{abstract}

Keywords: intuition talk, taste disagreements, linguistic corpora, intuition respecting

* Universidad de Valparaíso, Chile; member of the Centro de Estudios en Filosofía, Lógica y Epistemología from the Universidad de Valparaíso (Chile), and the FiloLab excellence group from the Universidad de Granada (Spain); e-mail: davidbordonaba@gmail.com; ORCID: https://orcid.org/oooo-0002-0788-9733.

** This article has partly been elaborated in the framework of the project A Computational Dynamic Analysis of Public Debates on Politics, Aesthetics and Taste, No 3180096 of FONDECYT postdoctoral competition 2018, funded by CONICYT / FONDECYT / POSTDOCTORADO / No Proyecto 3180096. I am grateful to two anonymous referees for their invaluable comments, and to the audiences of the Seminario de Filosofía y Matemáticas (Universidad de Valparaíso, Chile) and the GLiF Seminars (Universidad Pompeu Fabra, Spain), where I presented previous versions of this work. 


\section{INTRODUCTION}

The role of intuitions in analytic philosophy has been a subject of study and debate. The received view in many areas of the discipline (see Goldman 2007, Weinberg 2007, Williamson 2007: 2, Baz 2012: 87, Koopman 2012, Kornblith 2014) is that intuitions play a significant role - an idea that can be summarized in the so-called Thesis of Centrality, i.e., that analytic philosophers take intuitions as a source of evidence. For Cappelen (2012), the beginning of this influence traces back to thought experiments used to defend semantic externalism (see Putnam 1975, Kripke 1980) and other influential thought experiments, such as Mary's room (see Jackson 1982). However, for Hintikka (1999: 127), "[i]ntuitions came into fashion in philosophy as a consequence of the popularity of Noam Chomsky's linguistics and its methodology [after the mid-1960s]." Also, Cohen says that this tendency "began to prevail in the later 1940s. It then became fairly common, at least in North America, for intuitions to be explicitly invoked by philosophers" (Cohen 1986: 77, quoted by Andow 2015a: 189-190).

Although there is no clear consensus as to the exact date when this trend began, it seems clear that, sometime after the 1940s, analytic philosophers began to use intuitions when arguing for or against theories, and, for this reason, they began to talk about intuitions much more frequently - a trend that has continued to grow to this day. In other words, the "use of the word 'intuition' has exploded in analytic philosophy" (Andow 2015a: 190).

Experimental philosophy (see Knobe 2007, Knobe, Nichols 2007, Rose, Danks 2013, Hansen 2014, 2015, Hansen, Chemla 2015) was born in the early 21st century, in part, in reaction to those philosophers who use intuitions in philosophy. They oppose the so-called "method of cases" (Machery et al. 2004: B8) - i.e., justifying general theses by appeal to particular cases that elicit some sort of reaction in observers. Instead, they defend the necessity of applying methods from other disciplines to research in philosophy, mainly methods from cognitive science.

Herman Cappelen, a prominent leader of "intuition deniers" (Nado 2016: 782), argues that intuitions play no evidential role in analytic philosophy: "it is not true that philosophers rely extensively (or even a little bit) on intuitions as evidence" (Cappelen 2012: 1). Specifically, he identifies two arguments that have traditionally been used to defend the Thesis of Centrality: the Argument from "Intuition" Talk (AIT) and the Argument from Philosophical Practice (Cappelen 2012: 4). The latter is related to the specific methods 
analytic philosophers use to defend their theories. The former is associated with the vocabulary philosophers use ${ }^{1}$ when supporting their theories.

Cappelen (2012) identifies three questions that any study evaluating AIT should consider. First, a quantitative question: to what extent philosophers use intuition talk?2 Second, a centrality question: does intuition talk play a central role in philosophical arguments - for example, does it occur in essential parts of the argumentation? Third, an interpretative question: do the uses that philosophers make of intuition talk support the Thesis of Centrality, or can these uses be interpreted differently? Several studies focus on the quantitative question (see Andow 2015a, Ashton, Mizhari 2018) and the interpretative question (see Cappelen 2012, Tallant 2013, Andow 2015b). However, the second question has gone largely unnoticed.

This paper examines the centrality question to fill the gap left by the work investigating analytic philosophers' use of intuition talk. An exhaustive and comprehensive empirical investigation of intuition talk in a whole subdiscipline, such as epistemology or philosophy of language, would be a massive undertaking, so I have chosen to carry out a more restricted case study of the literature on "predicates of personal taste" (Lasersohn 2005) and "faultless disagreement" (see Kölbel 2004, MacFarlane 2014).

Before continuing, a clarification is in order. It could be argued that it is unreasonable to connect Cappelen's general statement about intuitions with the chosen case study because we may be talking about two different things when we speak of intuitions in epistemology - e.g., the intuitions triggered by thought experiments - and linguistic intuitions - e.g., those of grammaticality. However, the most relevant feature of both cases is their pretheoretical, effortless, or spontaneous character. As Cappelen himself acknowledges (Cappelen 2012: 33), if we are required to say what it means that an assertion or a belief is intuitive, we can surely do no more than remark on the pre-theoretical or effortless character of that belief or assertion. As can be seen, this applies both to linguistic intuitions and to intuitions triggered by thought experiments. Moreover, some authors (see, e.g., Shieber 2012) use linguistic intuitions as an explanatory model for intuitions in philosophy.

The paper is divided as follows. Section 1 presents AIT in depth. Section 2 discusses the methodologies available in the experimental philosophy of lan-

\footnotetext{
${ }^{1}$ Some philosophers (see, e.g., Williamson 2007, Ludwig 2010) distinguish two types of usage of intuition talk: everyday use and special philosophical use. However, since my aim is to empirically investigate the use of intuition talk in philosophical writing, investigating whether there are reasons to distinguish two types of use will not be relevant.

2 By "intuition talk," I refer specifically to the following terms: "intuit," "intuits," "intuition," "intuitions," "intuitive," "intuitively," "counterintuitive," and "counterintuitively."
} 
guage, questionnaires, and linguistic corpora, advocating the last option. Then, it presents the methods and the corpus used in the study. Section 3 explains the analyses carried out to check the centrality question in the literature of taste disagreements. Specifically, I perform a collocation and a concordance analysis. Finally, I discuss the results and assess whether intuition talk is central in the discussion on taste disagreements.

\section{THE ARGUMENT FROM “INTUITION" TALK}

AIT is related to the kind of vocabulary philosophers use when arguing for their theories. In a nutshell, if analytic philosophers think their theories should account for certain intuitions or if they use terms like "intuitive" in characterizing the examples they use, then intuitions are taken as evidence for such theories. However, Cappelen contends that AIT does not support the Thesis of Centrality:

I am inclined to put weight on what I think of as a verbal tick (or virus): philosophers started to use expressions such as "Intuitively, BLAH" a lot. . . . [A]ccording to this diagnosis, the usage itself is not motivated by (or anchored in) any substantive philosophical commitments or views about intuitions or philosophical methodology - it's simply a verbal tick without any interesting philosophical foundation (Cappelen 2012: 22).

In short, for Cappelen, AIT does not support the Thesis of Centrality because by using terms like "intuition" or "intuitive," analytical philosophers are merely exhibiting a verbal tick. In no case does the use of such terms indicate that intuitions count as evidence. As said in the Introduction, Cappelen identifies three questions that any study evaluating AIT should consider. First, a quantitative question, a centrality question, and an interpretative question. I briefly outline these three issues.

The quantitative question concerns the extent to which philosophers use intuition talk. Cappelen does not spell this first question out in detail. He only notes that answering it would involve studying analytic philosophy texts from 1950. This is not to deny that several studies directly address this issue. For example, Andow (2015a) notes a significant increase in the use of intuition talk in academia and, particularly, in analytic philosophy: "the proportion of philosophy articles indexed in JSTOR indulging in intuition talk has grown from around 22 percent in the decade 1900-1909 to around 54 percent in the decade 2000-2009" (Andow 2015a: 190). In this same vein, Ashton and Mizrahi (2018) showed that analytic philosophers had begun to use intuition talk much earlier than in the 1940s. They did a search using the JSTOR corpus 
and the HathiTrust database, which allowed them to conclude that "intuition talk goes all the way to the 180os" (Ashton, Mizrahi 2018: 599). Their analysis also shows that instances of intuition talk increase exponentially from the 1940s onwards, which is very much in line with Cohen (1986), and slightly less so with Hintikka (1999) and Cappelen (2012).

The interpretative question concerns the possible alternative interpretations of the Thesis of Centrality. In other words, do the uses that philosophers make of intuition talk support the Thesis of Centrality, or can these uses be interpreted differently? Cappelen argues that the use analytic philosophers make of intuition talk does not vindicate the Thesis of Centrality. He argues that terms like "intuitive" and "intuitively" act as speech-act modifiers, that is, as terms that are often used as "hedges" - expressions used to weaken the commitments the speaker undertakes in uttering some specific sentence (Cappelen 2012: 36). Cappelen distinguishes two reasons why a speaker may use a term as a hedge. He identifies an easy (audience-focused) (Cappelen 2012: 38) use, which indicates the tentative and incomplete nature of the proposition modified by the hedge, and contrasts it with a snap (speaker-focused) (Cappelen 2012: 38) use, which signals that the speaker has arrived at some proposition without much effort or reflection. When intuition talk is used as a hedge, intuitions are not taken as evidence. Therefore, AIT does not support Centrality.

Andow (2015b) confirms Cappelen's ideas. He shows that one of the main four uses of intuition talk he identifies in analytic philosophic writings is $I n$ tuition as Snap Judgment. This use indicates "that a judgment was not reached using elaborate or extensive reasoning or is intended for easy consumption" (Andow 2015b: 524). He also identifies three other uses of intuition talk: i) "Methodological ... indicating [negatively] an appeal to intuition in support of a position or claim" (Andow 2015b: 523); ii) "Intuition Can Be Misleading" which "indicate[s] that, at least with regard to the matter in hand, intuition is misleading in some way" (Andow 2015b: 523); and iii) "Intuition as Epistemically Positive," which summarizes those uses "in which saying something is intuitive seems to be used to say something positive about the relevant content" (Andow 2015b: 524).

Tallant (2013) investigates the use of intuitions in physics. Through corpus research using the keywords "intuitive" and "intuition," the paper distinguishes: i) cases where "a result is described [positively] as being intuitive" (Tallant 2013: 2967); ii) cases where theories or explanations are described as intuitive; iii) intuitive pictures; iv) "types of understanding described as intuitive" (Tallant 2013: 2969); v) cases where physicists speak of getting, building, or gaining some intuition about a subject matter; vi) cases in which "physicists will begin a sentence 'intuitively' and then go on to describe how 
they think a particular theoretical model will map onto a problem space" (Tallant 2013: 2970).

The centrality question concerns the role played by intuition talk in argumentation. It asks whether intuition talk appears in essential parts of argumentation, in marginal ones, or does not appear at all. Although Cappelen does not provide empirical data, he conjectures:

Let $\mathrm{Q}$ be a central question in any philosophical subdiscipline. By doing a simple and quick scholarly search, you will both find philosophers who present key arguments in connection with Q in an entirely "intuition"-free way and philosophers who present those same key arguments by using "intuition"-talk. (Cappelen 2012: 26)

As shown above, for Cappelen, any study of the role of intuition talk will show that there are authors who make use of intuitions in argumentation and other authors who do not use intuitions at all. As this is simply a conjecture, Cappelen does not go into any detail in explaining what kinds of roles intuitions might play in argumentation. For example, when intuitions are used as evidence, do they mostly appear as a premise, or do they also appear as a conclusion? Does the fact that they appear as a premise always indicate that the intuition is being used as evidence? These and many other related questions are relevant to the centrality question. Cappelen leaves this question unanalyzed, however, as do the other studies examining the use of intuitions in analytic philosophy.

In sum, the specialized literature analyzing intuition talk has focused on the quantitative and interpretative questions. To the best of my knowledge, no studies to date have examined the centrality question. This paper aims to complement these other works by analyzing this question in detail, which will be the focus of Section 4 .

\section{METHODS AND MATERIALS}

The use of linguistic corpora in experimental philosophy of language has been explicitly defended on more than one occasion in recent years (Bluhm 2013, 2016, Hansen, Chemla 2015, Hansen 2015, Caton 2020, Hinton 2020, Tallant, Andow 2020). Why should we use linguistic corpora? Although other quantitative methods, such as questionnaires, are entirely feasible, corpus methods have certain advantages: 
(a) Linguistic corpora, unlike questionnaires, are unbiased data sets. ${ }^{3}$ As Bluhm (2013: 12) puts it, corpora "data are, by and large, unfiltered."

(b) The amount of evidence considered is usually greater than with questionnaires. An example of this is the size of some of the free online corpora, such as the Corpus of Contemporary American English (COCA), with 560 million words, or the British National Corpus (BNC) with 100 million words.

(c) When using linguistic corpora, we usually analyze frequencies of particular terms or frequencies of the expressions that typically co-occur with them. However, corpora also provide the broader contexts in which the words appear. A detailed analysis of these broader contexts may uncover new features of the phenomenon under investigation.

(d) Computer processing allows us to perform automatic and more in-depth analyses. R Studio4 (see Desagulier 2017, Gries 2017) and \#Lancsbox 5 are the options chosen in this study to carry out the analyses.

To analyze the centrality question, I compiled a corpus comprising the full texts of different articles addressing taste disagreements. ${ }^{6}$ The articles were published from 2001 to 2020 . I chose twenty papers from each decade, which adds up to the total of 40 papers. To select the articles, I used the beta version of Constellate.7 I searched for philosophy articles containing the terms "personal taste" and "faultless disagreement." Then, I sorted the results according to relevance. As Andow highlights, "selecting the corpus in this way provides some assurances that the articles considered have gained attention in their field" (Andow 2015b: 522). Finally, I chose the top twenty papers in Constellate from the list for each decade. ${ }^{8}$ In alphabetical order, the twenty papers chosen from the 2001-2010 period are: Alwood, Schroeder (2009), Barker (2009), Barker (2010), Binderup (2008), Brogaard (2008, 2009), Francén (2010), Glanzberg (2007, 2009), Haslanger (2007), Kölbel (2008, 2009), Lasersohn

3 One of the most serious problems of questionnaires is the so-called "experimenter bias" (Strickland, Suben 2013: 457-459), according to which the research team, for example when designing the questionnaire, can influence the experiment in a way that makes it more likely that the expected result will be achieved.

4 https://www.r-project.org/.

5 http://corpora.lancs.ac.uk/lancsbox/.

${ }^{6}$ The search was conducted on March 23, 2021.

7 https://constellate.org/.

${ }^{8}$ I limited the maximum number of papers by the same author to two in order to avoid an unbalanced corpus. 
(2009), MacFarlane (2005), Moltmann (2010), Montminy (2009), Rowley, Robinson (2008), Stojanovic (2007), Weatherson (2009), and Wright (2007).

The twenty papers from the 2011-2020 decade are: Baker, Robson (2015), Capraru (2016), Carter (2014), Clapp (2015), Cohnitz, Marques (2014), Colomina-Almiñana (2015), Díaz (2016), Egan (2014), Eriksson, Tiozzo (2016), Hales (2014), Hîncu (2015), Huvenes (2014), Kompa (2015), Lasersohn (2011), López de Sa (2015), Miščević (2018), Moltmann (2012), OdrowążSypniewska (2013), Palmira (2014), and Stojanovic (2012).

I then processed the articles in R Studio to convert them to .txt. I edited them, performing two basic types of action: deleting the headings of each page and pasting the text of the footnotes just after the place where they appeared in the text. Finally, I combined them into a single .txt file to obtain the final corpus, which has a total word count of 367,590 . In the next section, I explain the different analyses devised to address the centrality question. Specifically, I carry out two types of analysis. First, a collocation analysis - i.e., an analysis of the words that most often co-occur with intuition talk. Second, a concordance analysis - i.e., an analysis of the most recurrent patterns of use of intuition talk.

\section{ANALYSES}

In both of the analyses, I focus on the collocates and patterns of use of "*intuit*," that is, of the root "intuit," because searching for that expression, it is possible to find the occurrences of "intuit," "intuits," "intuition," "intuitions," "intuitive," "intuitively," "counterintuitive," and "counterintuitively." In this sense, I consider "terminology of intuition" (Ashton, Mizrahi 2018: 596), but not "language indicating appeals to intuition" (Ashton, Mizrahi 2018: 596). Many terms may belong to this second category - for example, verbs "seem" or "appear," or nouns "impression" or "appearance." However, since one of the aims of the work is to conduct a detailed and meticulous analysis, I think it is better to focus on the expressions belonging to the first category.

Besides, the number of hits when searching for "*intuit*" was sufficiently high to only consider this type of terms in the analysis. A search for the root in the corpus yields 558 occurrences, which are distributed among the different words as follows: "intuitions" (258 occurrences), "intuition" (140 occurrences), "intuitively" (69 occurrences), "intuitive" (59 occurrences), "intuit" (12 occurrences), "counterintuitive" (6 occurrences), "intuits" (5 occurrences), "intu- 
itionism" (5 occurrences), 9 "counterintuitively" (3 occurrences), "unintuitive" (1 occurrence). In the remainder of this section, I present in detail the two analyses carried out to determine the centrality of intuition talk.

\subsection{COLLOCATION ANALYSIS}

A collocation analysis determines the intuition talk collocates - that is, which words most often co-occur with intuition talk. Collocation is "the tendency of words to be biased in the way they co-occur" (Hunston 2002: 68). In other words, collocates are the words that occur "frequently within the neighborhood of another word, normally more often than we would expect the two words to appear together because of chance" (Baker, Gabrielatos, McEnery 2013: 36). The idea is that, by seeing which types of words usually co-occur with intuition talk, we can get a preliminary idea of the role intuition talk plays in philosophical argumentation.

To perform this analysis, I used the \#Lancsbox's GraphColl tool, which identifies the collocations of a search item (or "node"), showing them in a table. It allows us to define the score (the statistical significance measure), the span (how many words to the left and the right of the node are to be considered), the collocate threshold (the minimum number of times a word has to appear in the span defined to be considered a collocate), and the statistical score threshold (the minimum value of a collocate to be considered statistically significant).

When searching with the \#Lancsbox GraphColl tool, I focused on the nouns, verbs, and adjectives that usually collocate with "*intuit*,"10 using a 5:5 span and a collocate threshold of 10. Regarding the statistical scores, I used the MI score. The "MI-score indicates the strength of a collocation. It compares the actual co-occurrence of the two items [the node and the collocate] with their expected co-occurrence if the words in the corpus used were to occur in a totally random order. In other words, the MI-score measures the amount of non-randomness present when two words co-occur" (Hunston 2002: 71). An MI-score higher than 3 is frequently considered significant (see Hunston 2002: 71, Baker 2006: 101).

First, let us see the top ten noun collocates of "*intuit*" in a 5:5 span, using an MI-score higher than 3, and a collocate threshold of 10. The collocates' specific positions (whether they appear to the left, to the right or on both sides

\footnotetext{
9 The five cases of "intuitionism" were discarded in subsequent analyses since they all refer to the name of an article and do not imply an effective use of intuition talk.

${ }^{10}$ By doing this, I leave out definite and indefinite articles, prepositions, such as "of," and conjunctions, such as "and," which tend to appear as collocates of almost any term in practically any search.
} 
of the node), their MI-score values, absolute frequencies as collocates, and absolute frequencies in the corpus of each collocate are presented in Table 1.

\begin{tabular}{llccc}
\hline \multicolumn{1}{c}{ Place } & Collocate & MI-score & Freq. (coll.) & Freq. (corpus) \\
\hline Left & intra-context & 9.68076 & 10 & 8 \\
\hline Left & hearer & 7.53286 & 11 & 39 \\
\hline Left & rise & 7.30298 & 19 & 79 \\
\hline Left & faultlessness & 5.93257 & 20 & 215 \\
\hline Left & explanation & 5.60881 & 11 & 148 \\
\hline Left & people & 5.50417 & 15 & 217 \\
\hline Both & intuition & 5.42265 & 26 & 398 \\
\hline Right & disagreement & 5.34682 & 157 & 2533 \\
\hline Left & truth-value & 5.32070 & 14 & 230 \\
\hline Right & notion & 4.85210 & 15 & 341 \\
\hline
\end{tabular}

Table 1. Top ten noun collocates of “*intuit*" using MI-score

Then, I did the same for the verb collocates. The collocates' specific positions, their MI-score values, absolute frequencies as collocates, and absolute frequencies in the corpus of each collocate are presented in Table 2.

\begin{tabular}{llccc}
\hline \multicolumn{1}{c}{ Place } & Collocate & MI-score & Freq. (coll.) & Freq. (corpus) \\
\hline Left & confirm & 8.49210 & 17 & 31 \\
\hline Left & trigger & 7.69587 & 12 & 38 \\
\hline Left & explain & 6.32136 & 38 & 312 \\
\hline Left & account & 6.24336 & 18 & 156 \\
\hline Left & give & 5.05450 & 33 & 652 \\
\hline Left & seem & 4.73080 & 22 & 544 \\
\hline Right & concern & 4.69414 & 11 & 279 \\
\hline Right & think & 4.14721 & 18 & 667 \\
\hline Left & can & 4.13472 & 45 & 1680 \\
\hline Right & disagree & 4.07343 & 12 & 468 \\
\hline
\end{tabular}

Table 2. Top ten verb collocates of “*intuit *” using MI-score 
Finally, I analyzed the adjective collocates. The collocates' specific positions, their MI-score values, absolute frequencies as collocates, and absolute frequencies in the corpus of each collocate are presented in Table 3.

\begin{tabular}{llccc}
\hline \multicolumn{1}{c}{ Place } & Collocate & MI-score & Freq. (coll.) & Freq. (corpus) \\
\hline Left & unstable & 9.43283 & 20 & 19 \\
\hline Left & stable & 8.92587 & 20 & 27 \\
\hline Right & reliable & 8.49634 & 11 & 20 \\
\hline Right & ordinary & 5.41241 & 12 & 185 \\
\hline Right & relative & 5.40360 & 45 & 698 \\
\hline Right & moral & 4.68142 & 17 & 435 \\
\hline Left & faultless & 4.60535 & 38 & 1025 \\
\hline Both & different & 4.09546 & 22 & 845 \\
\hline Left & other & 3.87824 & 20 & 893 \\
\hline Left & such & 3.49322 & 13 & 758 \\
\hline
\end{tabular}

Table 3. Top ten adjective collocates of “*intuit*" using MI-score

The MI-Score has some peculiarities that can make the analyses unreliable, however. According to Hunston (2002: 72), "knowing the strength of the collocation [its MI-score] is not always a reliable indication of meaningful association." As Baker (2006: 102) stresses, "one problem with MI is that it can tend to give high scores to relatively low frequency words." Thus, as Hunston (2002: 73) puts it, "we also need to know how much evidence there is for it [the collocation], that is, how certain we can be that the collocation is the result of more than the vagaries of a particular corpus." To deal with this potential problem, I repeated the analysis using the t-score because the $\mathrm{t}$-score takes the amount of evidence into account. In considering the corpus size, the $\mathrm{t}$-score is a measure of certainty of collocation. A t-score higher than two is usually considered significant (see Hunston 2002: 73).

First, let us see the top ten noun collocates of "**intuit" in a 5:5 span, using a t-score higher than 3, and a collocate threshold of 10. The collocates' specific positions, their t-scores, absolute frequencies as collocates, and absolute frequencies in the corpus of each collocate are presented in Table 4. 


\begin{tabular}{llccc}
\hline \multicolumn{1}{c}{ Place } & Collocate & t-score & Freq. (coll.) & Freq. (corpus) \\
\hline Right & disagreement & 12.22207 & 157 & 2533 \\
\hline Right & truth & 7.41367 & 60 & 1690 \\
\hline Left & relativism & 5.49110 & 33 & 956 \\
\hline Both & intuition & 4.98014 & 26 & 398 \\
\hline Left & faultlessness & 4.39891 & 20 & 215 \\
\hline Left & rise & 4.33129 & 19 & 79 \\
\hline Left & sentence & 4.28290 & 22 & 1255 \\
\hline Right & case & 4.21333 & 21 & 1111 \\
\hline Right & assertion & 4.0692 & 19 & 829 \\
\hline Left & speaker & 3.85049 & 17 & 738 \\
\hline
\end{tabular}

Table 4. Top ten noun collocates of "*intuit "* using t-score

Then, I did the same for the verb collocates. The collocates' specific positions, their MI-score values, absolute frequencies as collocates, and absolute frequencies in the corpus of each collocate are presented in Table 5 .

\begin{tabular}{lllcc}
\hline \multicolumn{1}{c}{ Place } & Collocate & t-score & Freq. (coll.) & Freq. (corpus) \\
\hline Right & be & 14.92261 & 275 & 18080 \\
\hline Left & have & 7.13401 & 58 & 2409 \\
\hline Left & can & 6.32632 & 45 & 1682 \\
\hline Left & explain & 6.08732 & 38 & 312 \\
\hline Left & give & 5.57170 & 33 & 652 \\
\hline Left & seem & 4.51377 & 22 & 544 \\
\hline Left & do & 4.42922 & 24 & 1511 \\
\hline Left & account & 4.18663 & 18 & 156 \\
\hline Left & confirm & 4.11165 & 17 & 31 \\
\hline Right & think & 4.00319 & 18 & 667 \\
\hline
\end{tabular}

Table 5. Top ten verb collocates of “*intuit"” using t-score 
Finally, I analyzed the adjectives that most often co-occur with intuition talk. The collocates' specific positions, their MI-score values, absolute frequencies as collocates, and absolute frequencies in the corpus of each collocate are presented in Table 6 .

\begin{tabular}{lllcc}
\hline \multicolumn{1}{c}{ Place } & Collocate & t-score & Freq. (coll.) & Freq. (corpus) \\
\hline Right & relative & 6.54972 & 45 & 698 \\
\hline Left & faultless & 5.91116 & 38 & 1025 \\
\hline Left & unstable & 4.46566 & 20 & 19 \\
\hline Left & stable & 4.46294 & 20 & 27 \\
\hline Both & different & 4.41603 & 22 & 845 \\
\hline Left & other & 4.16801 & 20 & 893 \\
\hline Right & moral & 3.96242 & 17 & 435 \\
\hline Right & ordinary & 3.38276 & 12 & 185 \\
\hline Right & reliable & 3.30744 & 11 & 20 \\
\hline Left & such & 3.28536 & 13 & 758 \\
\hline
\end{tabular}

Table 6. Top ten adjective collocates of “*intuit "*” using t-score

\subsection{CONCORDANCE ANALYSIS}

Some authors (Sinclair 2004, Partington, Duguid, Taylor 2013) contend that the basic units of meaning are not single words but clusters thereof. A common way to observe this is through a concordancer, i.e., a tool that allows us to search a corpus for a specific term and visualize recurring usage patterns associated with that term.

I performed a concordance analysis with the \#Lancsbox' KWIC tool to observe recurrent patterns involving intuition talk. This tool generates a list of all instances of a search item, showing the node in a central column, and on each side, columns containing a small part of the context (the defined span) that precedes and follows each search result in the corpus.

First, I searched for the expression "*intuit" in a 7:7 span (seven words to the left and seven words to the right of the node). Ordering the left span results in alphabetical order, two main patterns stand out from the rest: 
(a) explain(s) / explaining / explanation + away / the / of the / our / for / these + intuition(s) / intuitive / disagreement intuition / faultless intuition / unstable intuitions (25 occurrences)

(b) account(s) / accounting + for / of + the / our / stable / this / these + intuition(s) / intuitive / disagreement intuition / faultless(ness) intuition (20 occurrences)

Other patterns worth mentioning include:

(c) relative truth / truth-conditional / truth-value + intuitions (19 occurrences)

(d) confirm(s) / confirming + our / some people's / the stable / the unstable / this / these + intuition(s) (15 occurrences)

(e) give(s) / giving + rise to + intuitions / relative-truth intuitions (15 occurrences)

(f) unstable + intuitions (15 occurrences)

(g) trigger(s) + [our/the/this/peoples' $]^{11}+$ intuition(s) / faultlessness intuition (9 occurrences)

(h) seem(s) + intuitive(ly) (7 occurrences)

(i) have + unstable / stable intuitions (6 occurrences)

Then, ordering the right span results in alphabetical order, I noticed the following patterns:

(a) intuition(s) + about/of + conflict/contradiction/disagreement(s) (65 occurrences)

(b) intuition(s) of + relative truth (32 occurrences)

(c) intuition(s) of + faultless disagreement/faultlessness (11 occurrences)

(d) intuitions + are [a] + reliable/unreliable/reliable guide(s) (9 occurrences)

(e) intuitive + notion of (9 occurrences)

(f) intuitively + think (7 occurrences)

(g) intuitions + can concern/concerning (6 occurrences)

\footnotetext{
${ }^{11}$ Square brackets indicate that the expression is optional.
} 


\section{DISCUSSION}

Before discussing the results of the two analyses, it is worth commenting on which collocates and which patterns are relevant for the discussion. Let us start with the collocation analysis. The nouns "rise," "intuition," "faultlessness," and "disagreement" are statistically significant when using both MI and t-score. The collocates verbs are considerably more uniform since seven of the ten are repeated: "can," "explain," "seem," "give,"12 "account," "confirm," and "think." Regarding the adjectives, we obtain exactly the same collocates using MI and t-score.

The concordance analysis confirms the relevance of many of these terms. Specifically, the most common patterns involve the nouns "disagreement," "faultlessness," "conflict," "contradiction," "truth-value," and "relative truth," the verbs "explain," "account," "give," "confirm," "think," "trigger," and "seem," and the adjectives "faultless," "unstable," "stable," "reliable," "unreliable," and "truth-conditional."

Considering the nouns and the adjectives that are significant under both statistical scores, we can highlight two types of intuitions as relevant to the debate: intuitions of faultlessness and intuitions of disagreement. The pattern intuition(s) + about / of + conflict / contradiction / disagreement(s) appears 65 times in the corpus, while the pattern intuition(s) of + faultless disagreement / faultlessness appears 11 times in the corpus. Moreover, they appear frequently in two other common patterns, namely those involving the verbs "explain" and "account," and in expressions such as "explain our disagreement intuition" or "account for our faultlessness intuition." As shown above, there is another type of intuition that is quite common in the corpus: intuitions of truth value and relative truth. Specifically, the pattern intuition(s) of + relative truth appears 32 times in the corpus, while the pattern relative truth / truth-conditional / truth-value + intuitions appears 19 times in the corpus. However, I disregarded these patterns because most of their occurrences were clustered in two authors: the former pattern appears 18 times in Moltmann (2010) and 13 times in Moltmann (2012), whereas the latter pattern appears six times in Moltmann (2010) and ten in Capraru (2016). In other words, these patterns are not representative of the corpus but rather of the papers' topic and, more particularly, of their authors.

\footnotetext{
${ }^{12}$ Strictly speaking, the collocates are neither "rise" nor "give," but the phrasal verb "give rise to." However, they appear separately because automatic syntactic parsing discriminates sign strings at the word level.
} 
Among the verbs that are significant under both statistical scores, several are relevant but two stand out, namely "account" and "explain." The frequency of the verbs "account" and "explain" shows that they are strong collocates of intuition talk. The verb "explain" has an MI-score of 6.32 and a t-score of 6.18, whereas the verb "account" has an MI-score of 6.24 and a t-score of 4.08. Both scores are above the minimum to consider a collocate as statistically significant, which, let us recall, was 3 for the MI-score and 2 for the t-score. Moreover, the verbs "account" and "explain" appear in two of the most common patterns: explain(s) / explaining / explanation + away / the / of the / our / for / these + intuition(s) / intuitive / disagreement intuition / faultless intuition / unstable intuition(s) appears 25 times in the corpus, while account(s) / accounting + for / of + the / our / stable / this / these + intuition(s) / intuitive / disagreement intuition / faultless(ness) intuition appears 20 times in the corpus.

There are two other verbs that also have a high frequency and appear in widely used patterns. These verbs are "confirm" and "give." The first has the highest MI-score, 8.49, and a t-score of 4.11; the second has an MI-score of 5.05 and a t-score of 5.57. Moreover, they appear in common patterns: confirm(s) / confirming + our / some people's / the stable / the unstable / this / these + intuition(s) appears 15 times in the corpus, while give(s) / giving + rise to + intuitions / relative-truth intuitions also appears 15 times in the corpus. However, I had to discard these two verbs, and the patterns in which they appear, because a detailed examination of the distribution shows that most of the occurrences are concentrated in just a few papers. Specifically, confirm(s) / confirming + our / some people's / the stable / the unstable / this / these + intuition(s) appears 12 times in Francén (2010), and give(s) / giving + rise to + intuitions / relative-truth intuitions appears 11 times in Moltmann (2012). In contrast, the patterns involving "explain" or "account" are distributed throughout the whole corpus.

To sum up, when analytic philosophers discuss taste disagreements, the intuitions that matter most are intuitions of disagreement and intuitions of faultlessness. To some extent, this is something that could have been stated without the need for any analysis. However, the other result is unexpected and, more importantly, meaningful and revealing because the two most relevant verbs for understanding the use of intuition talk in the discussion on taste disagreements, namely "explain" and "account," are very similar. A careful examination of the patterns in which they occur shows that, in both cases, their uses point to the same idea: there is a set of intuitions, intuitions of faultlessness and disagreement, that needs to be explained. In fact, both 
are directly related to a specific use of intuitions as evidence, namely "intuition respecting" (Andow forthcoming: 5-6).

Andow (forthcoming) distinguishes six types of practices in which analytic philosophers use intuitions as evidence: i) case wielding - that is, real or imaginary cases that elicit certain intuitions that are then adduced as evidence for or against a thesis or theory; ii) idea motivating refers to those cases where the problem we are dealing with is motivated by some common intuitions, and these intuitions are established as partial evidence to give a philosophical solution to the problem; iii) assumption footstamping is the practice of taking for granted certain propositions, described as intuitions, for the sake of argument defended in a debate or a paper; iv) intuition respecting points to the practice of providing certain ideas, described as intuitions, which any theory that satisfactorily explains a given phenomenon should respect; v) weights and balances philosophy is similar to intuition respecting but it is not so rigid in that it does not require a theory to respect specific desiderata but evaluates the theory to the extent that it respects or can accommodate one or more intuitive ideas; vi) negotiating dilemmas, inconsistent triads, and so on refers to cases where philosophers face a dilemma - they construct it as consisting of two or more intuitive ideas and then conduct the subsequent philosophical debate focusing on these ideas.

According to the fourth sense distinguished in Andow (forthcoming), when philosophers contend that theory A better explains phenomenon $\mathrm{C}$ because A can account for intuitions related to C that B cannot, they are using those intuitions as evidence to adopt theory A. In other words, in those cases philosophers are contending that theory A explains C better than B because A respects the intuitions related to $\mathrm{C}$. And this is what happens in the case at hand. Analytic philosophers discussing taste disagreements use intuitions as evidence because they contend that a specific theory (e.g., deictic contextualism, non-deictic contextualism, or relativism) is the best candidate to explain a given phenomenon (i.e., taste disagreements) because the theory can accommodate certain intuitions (e.g., faultlessness and disagreement intuitions) better than others. How they express themselves, specifically the verbs they use most frequently with intuition talk or the most common patterns they use, supports this. Consider the following examples:

The conclusion is that neither proposition relativism nor assertion relativism can confirm the stable intuitions we (or at least many of us) have about moral disagreement. Only absolutism can do that, it seems. This does not rule out any of the two forms of relativism, of course, since it might still be possibly [sic] for relativists to explain away our intuitions. But it means that relativism does not necessarily have an advantage over contextualism when it comes to explaining intuitions about disagreements in areas 
where we have strong such intuitions. For contextualists might also be able to explain away these intuitions about disagreement, perhaps in the same or similar ways as relativists can. (Francén 2010: 31)

Consequently, even if this account yields a sense in which the parties' judgments are faultless, it is far from obvious whether it [Prichard's epistemic relativism] accounts for our intuitions [of faultlessness] better than other accounts. (Eriksson, Tiozzo 2016: 1529)

Kölbel complains that the assumption of objective normative facts about taste fails to explain the intuition that the deliciousness of a beer is less objective than how many are left in the refrigerator. However, relativism about taste fails to explain why we routinely acknowledge that there are bona fide experts about beer, wine, whiskey, etc. As far as intuitions about taste go, they do not come down squarely on the side of the relativists. (Hales 2014: 77)

In contrast, examples like "Roller coasters are fun" / "Roller coasters are not fun," provoke a sense of direct contradiction, and not merely "disagreement" in the broad sense. The challenge for semantic theory is in accounting for this intuition of direct contradiction and simultaneously for the intuition of faultlessness which such examples produce. (Lasersohn 2011: 436)

Some philosophers writing on the possibility of faultless disagreement have argued that the only way to account for the intuition that there could be disagreements which are faultless in every sense is to accept a relativistic semantics. In this article we demonstrate that this view is mistaken by constructing an absolutist semantics for a particular domain - aesthetic discourse - which allows for the possibility of genuinely faultless disagreements. (Baker, Robson 2015: 429)

As shown in all these paragraphs, intuitions of faultlessness and intuitions of disagreement are central to these arguments because their advocates argue for (or against) a specific theory to the extent that it respects (or does not respect) these intuitions. In this sense, the two intuitions cited above are taken as evidence (in the sense of "intuition respecting") in the case for or against one of the relevant theories in the debate on taste disagreements. Andow (forthcoming) highlights that practices involving the use of intuitions need not necessarily imply that those intuitions are used as evidence. He contends that philosophers may use intuitions in "explanatory contexts," where "the aim is not to provide evidence for theories; a context in which the primary aim is simply to communicate unfamiliar thoughts; the aim is that someone else comes to understand what you are on about" (Andow forthcoming: 11). Although there may be cases such as those shown by Andow, the patterns involving "explain" and "account" point to the idea that intuitions are used primarily as evidence because, in both patterns, something explains or accounts for the intuitions of faultlessness and disagreement and this, as the examples show, is usually a particular theory. Besides, all the above examples are cases of explicit defenses of specific theories. These explicit defenses, as 
well as the arguments based on the idea of intuition respecting that they imply, are evidenced by the use of terms such as "conclusion," "far from obvious," "have an advantage," "fails to explain," "the challenge for semantic theory is," or "this view is mistaken."

In sum, intuition talk takes pride of place in the literature on taste disagreements because the argumentative practices of analytic philosophers are focused on the production and vindication of theories that respect the intuitions of faultlessness and disagreement. This is not to say that intuitionrespecting is the only sense in which intuitions are used as evidence. For example, the patterns give(s )/giving + rise to + intuitions / relative-truth intuitions and trigger(s) + [our / the / this / peoples'] + intuition(s) / faultlessness intuition seem to be best interpreted by the idea of case wielding. However, as mentioned, these patterns are not representative of the corpus. In contrast, the patterns involving the idea of accounting or explaining intuitions of faultlessness and disagreement appear throught the corpus and, in this sense, are representative of a much larger number of authors.

\section{CONCLUSION}

In this paper, I have explored how central intuition talk is in the discussion on taste disagreements. To this end, I compiled a corpus of relevant works in the area, and then ran two types of analyses on the corpus. First, a collocation analysis was run to determine the nouns, verbs, and adjectives that most frequently co-occur with intuition talk. Second, a concordance analysis was run to determine the patterns involving intuition talk that analytic philosophers use most frequently. The collocation analyses singled out several terms as statistically significant collocations: nouns "faultlessness" and "disagreement," verbs "confirm," "trigger," "explain," "account," and "seem," and adjectives "faultless," "reliable," "unstable," and "truth-conditional." The concordance analysis distinguished several patterns as statistically significant. However, only some of these patterns were sufficiently recurrent while appearing throughout the entire corpus. They include:

a) intuition(s) + about / of + conflict / contradiction / disagreement(s)

b) intuition(s) of + faultless disagreement / faultlessness

c) explain(s) / explaining / explanation + away / the / of the / our / for / these + intuition(s) / intuitive / disagreement intuition / faultless intuition / unstable intuition(s) 
d) account(s) / accounting + for / of + the / our / stable / this / these + intuition(s) / intuitive / disagreement intuition / faultless(ness) intuition.

In short, when analytic philosophers discuss taste disagreements, they consider mainly two types of intuitions, namely faultlessness and disagreement intuitions. Moreover, given how they argue for or against a given theory or thesis, it is clear that these theories should account for or explain these intuitions. Specifically, they use expressions like "far from obvious," "have an advantage," "fails to explain," "the challenge for semantic theory is," and "this view is mistaken" in characterizing how a given theory accounts or does not account for faultlessness and disagreement intuitions. In other words, a theory is a good theory for explaining taste disagreements to the extent that it respects faultlessness and disagreement intuitions. In this sense, the use authors make of intuition talk is directly related to "intuition respecting," a specific use of intuitions as evidence.

Investigating to what extent these results may be extrapolated to other debates or other subdisciplines within analytic philosophy is one of the next steps for subsequent analyses focused on the centrality of intuition talk. It is possible that the results of this paper only apply to the specific case studied and that those who argue that intuitions are not central to the argumentation practice of analytic philosophers are right. Alternatively, the results obtained in the present paper may apply to other debates, thus tipping the balance towards those who argue that intuitions play a central role in argumentative practices in analytic philosophy. This paper is a humble first step toward a deeper understanding of the role of intuitions in philosophical practice.

\section{BIBLIOGRAPHY}

Alwood A., Schroeder M. (2009), "From Outside the Ethics," Ethics 119(4), 805-813. https://doi.org/10.1086/605308

Andow J. (2015a), “How 'Intuition' Exploded,” Metaphilosophy 46(2), 189-212. https:// doi.org/10.1111/meta.12127

Andow J. (2015b), "How Distinctive is Philosophers' Intuition Talk?," Metaphilosophy 46(4-5), 515-538. https://doi.org/10.1111/meta.12151

Andow J. (forthcoming), “If Philosophers Aren't Using Intuitions as Evidence, What Are They Doing?," Dialectica.

Ashton Z., Mizrahi M. (2018), "Intuition Talk Is not Methodologically Cheap: Empirically Testing the 'Received Wisdom' about Armchair Philosophy,” Erkenntnis 83, 595-612. https://doi.org/10.1007/s10670-017-9904-4

Baker P. (2006), Using Corpora in Discourse Analysis, London: Continuum. 
Baker P., Gabrielatos C., McEnery T. (2013), Discourse Analysis and Media Studies: The Representation of Islam in the British Press, Cambridge: Cambridge University Press. https://doi.org/10.1017/CBO9780511920103

Baker C., Robson J. (2015), "An Absolutist Theory of Faultless Disagreement in Aesthetics," Pacific Philosophical Quarterly 98(3), 429-448. https://doi.org/10.1111/papq.12102

Barker C. (2009), "Clarity and the Grammar of Skepticism," Mind \& Language 24(3), 253273. https://doi.org/10.1111/j.1468-0017.2009.01362.x

Barker S. (2010), "Cognitive Expressivism, Faultless Disagreement, and Absolute but Nonobjective Truth,” Proceedings of the Aristotelian Society 110, 183-199. https://doi.org/ 10.1111/j.1467-9264.2010.00283.x

Baz A. (2012), When Words Are Called for: A Defense of Ordinary Language Philosophy, Cambridge-London: Cambridge University Press. https://doi.org/10.4159/harvard. 9780674064775

Binderup L. (2008), "Brogaard's Moral Contextualism," The Philosophical Quarterly 58(232), 410-415. https://doi.org/10.1111/j.1467-9213.2007.543.x

Bluhm R. (2013), "Don't Ask, Look! Linguistic Corpora as a Tool for Conceptual Analysis" [in:] Was dürfen wir glauben? Was sollen wir tun? Sektionsbeiträge des achten internationalen Kongresses der Gesellschaft für Analytische Philosophie e.V., M. Hoeltje, T. Spitzley, W. Spohn (eds.), DuEPublico, 7-15. https://nbn-resolving.org/urn:nbn:de: hbz:464-20130612-081113-3

Bluhm R. (2016), "Corpus Analysis in Philosophy" [in:] Evidence, Experiment and Argument in Linguistics and Philosophy of Language, M. Hinton (ed.), Oxford: Peter Lang, 91-109.

Brogaard B. (2008), "Moral Contextualism and Moral Relativism," The Philosophical Quarterly 58(232), 385-409. https://doi.org/10.1111/j.1467-9213.2007.543.x

Brogaard B. (2009), "Introduction to Relative Truth," Synthese 166(2), 215-229. https:// doi.org/10.1007/s11229-007-9288-0

Cappelen H. (2012), Philosophy without Intuitions, Oxford: Oxford University Press. https://doi.org/10.1093/acprof:oso/9780199644865.001.0001

Capraru M. D. I. (2016), "Objective Truth in Matters of Taste," Philosophical Studies 173(7), 1755-1777. https://doi.org/10.1007/s11098-015-0577-z

Carter J. A. (2014), "Disagreement, Relativism and Doxastic Revision," Erkenntnis 79, 155172. https://doi.org/10.1007/s10670-013-9450-7

Caton J. N. (2020), "Using Linguistic Corpora as a Philosophical Tool," Metaphilosophy 51(1), 51-70. https://doi.org/10.1111/meta.12405

Clapp L. (2015), “A Non-alethic Approach to Faultless Disagreement," Dialectica 69(4), 517-550. https://doi.org/10.1111/1746-8361.12104

Cohnitz D., Marques T. (2014), “Disagreements,” Erkenntnis 79, 1-10. https://doi.org/ 10.1007/s10670-013-9442-7

Colomina-Almiñana J. J. (2015), "Disagreement and the Speaker's Point of View," Language and Dialogue 5(2), 224-246. https://doi.org/10.1075/ld.5.2.02col

Cohen L. J. (1986), The Dialogue of Reason, Cambridge: Cambridge University Press.

Desagulier G. (2017), Corpus Linguistics and Statistics with R: Introduction to Quantitative Methods in Linguistics, Cham: Springer. https://doi.org/10.1007/978-3-319-64572-8

Díaz J. (2016), "Evaluative Disagreements," Teorema: Revista Internacional de Filosofía 35(1), 67-87. 
Egan A. (2014), "There's Something Funny About Comedy: A Case Study in Faultless Disagreement," Erkenntnis 79, 73-100. https://doi.org/10.1007/s10670-013-9446-3

Eriksson J., Tiozzo M. (2016), "Matters of Ambiguity: Faultless Disagreement, Relativism and Realism," Philosophical Studies 173(6), 1517-1536. https://doi.org/10.1007/s11098015-0561-7

Francén R. (2010), "No Deep Disagreement for New Relativists," Philosophical Studies 151(1), 19-37. https://doi.org/10.1007/s11098-009-9414-6

Glanzberg M. (2007), “Context, Content, and Relativism,” Philosophical Studies 136(1), 129. https://doi.org/10.1007/s11098-007-9145-5

Glanzberg M. (2009), "Semantics and Truth Relative to a World," Synthese 166(2), 281307. https://doi.org/10.1007/s11229-007-9285-3

Goldman A. (2007), "Philosophical Intuitions: Their Target, Their Source and Their Epistemic Status," Grazer Philosophische Studien 4, 1-26. https://doi.org/10.1163/9789401204 651_002

Gries S. T. (2017), Quantitative Corpus Linguistics with R: A Practical Introduction, New York: Routledge. https://doi.org/10.4324/9781315746210

Hales S. D. (2014), "Motivations for Relativism as a Solution to Disagreements," Philosophy 89(347), 63-82. https://doi.org/10.1017/Soo3181911300051X

Hansen N. (2014), "Contemporary Ordinary Language Philosophy," Philosophy Compass 9(8), 556-569. https://doi.org/10.1111/phc3.12152

Hansen N. (2015), "Experimental Philosophy of Language" [in:] Oxford Handbooks Online, Oxford: Oxford University Press. https://doi.org/10.1093/oxfordhb/9780199935314. 013.53

Hansen N., Chemla E. (2015), "Linguistic Experiments and Ordinary Language Philosophy," Ratio 28(4), 422-445. https://doi.org/10.1111/rati.12112

Haslanger S. (2007), “'But Mom, Crop-Tops Are Cute!' Social Knowledge, Social Structure and Ideology Critique," Philosophical Issues 17, 70-91. https://doi.org/10.1111/j.15336077.2007.00123.x

Hîncu M. (2015), "Predicates of Personal Taste and Faultless Disagreement," Logos \& Episteme 6(2), 160-185. https://doi.org/10.5840/logos-episteme20156210

Hintikka J. (1999), “The Emperor's New Intuitions,” Journal of Philosophy 96(3), 127-147. https://doi.org/10.2307/256466o

Hinton M. (2020), "Corpus Linguistics Methods in the Study of (Meta)Argumentation," Argumentation. https://doi.org/10.1007/s10503-020-09533-z

Hunston S. (2002), Corpora in Applied Linguistics, Cambridge: Cambridge University Press. https://doi.org/10.1017/CBO9781139524773

Huvenes T. T. (2014), “Disagreement Without Error," Erkenntnis 79, 143-154. https:// doi.org/10.1007/s10670-013-9449-0

Jackson F. (1982), “Epiphenomenal Qualia,” The Philosophical Quarterly 32(127), 127-136. https://doi.org/10.2307/2960077

Knobe J. (2007), “Experimental Philosophy,” Philosophy Compass 2(1), 81-92. https:// doi.org/10.1111/j.1468-0017.2009.01370.x

Knobe J., Nichols S. (2007), “An Experimental Philosophy Manifesto” [in:] Experimental Philosophy, J. Knobe, S. Nichols (eds.), New York: Oxford University Press, 3-14.

Kölbel M. (2004), "Faultless Disagreement," Proceedings of the Aristotelian Society 104(1), 53-73. https://doi.org/10.1111/j.0066-7373.2004.00081.x

Kölbel M. (2008), "Truth in Semantics," Midwest Studies in Philosophy 32 (1), 242-257. 
Kölbel M. (2009), “The Evidence for Relativism,” Synthese 166(2), 375-395. https://doi.org/ $10.1007 / \mathrm{s} 11229-007-9281-7$

Kompa N. (2015), “Contextualism and Disagreement," Erkenntnis 80, 137-152. https:// doi.org/10.1007/s10670-014-9663-4

Koopman C. (2012), "Pragmatist Resources for Experimental Philosophy: Inquiry in Place of Intuition,” The Journal of Speculative Philosophy 26(1), 1-24. https://doi.org/ 10.5325/jspecphil.26.1.0001

Kornblith H. (2014), "Naturalism and Intuitions" [in:] A Naturalistic Epistemology: Selected Papers, Oxford: Oxford University Press, 158-177. https://doi.org/10.1093/ acprof:oso/9780198712459.003.0011

Kripke S. A. (1980), Naming and Necessity, Oxford: Basil Blackwell.

Lasersohn P. (2005), "Context Dependence, Disagreement and Predicates of Personal Taste," Linguistics and Philosophy 28, 643-686. https://doi.org/10.1007/s10988-0050596-x

Lasersohn P. (2009), "Relative Truth, Speaker Commitment, and Control of Implicit Arguments," Synthese 166(2), 359-374. https://doi.org/10.1007/s11229-007-9280-8

Lasersohn P. (2011), "Context, Relevant Parts and (Lack of) Disagreement over Taste," Philosophical Studies 156(3), 433-439. https://doi.org/10.1007/s11098-010-9625-x

Ludwig K. (2010). "Intuitions and Relativity," Philosophical Psychology 23(4), 427-445. https://doi.org/10.1080/09515089.2010.505877

López de Sa D. (2015), "Expressing Disagreement: A Presuppositional Indexical Contextualist Relativist Account,” Erkenntnis 80, 153-165. https://doi.org/10.1007/s10670014-9664-3

MacFarlane J. (2014), Assessment-Sensitivity: Relative Truth and its Applications, New York: Oxford University Press. https://doi.org/10.1093/acprof:oso/9780199682751. 001.0001

MacFarlane J. (2005), "Making Sense of Relative Truth," Proceedings of the Aristotelian Society 105, 305-323. https://doi.org/10.1111/j.0066-7373.2004.00116.x

Machery E., Mallon R., Nichols S., Stich S. (2004), "Semantics, Cross-Cultural Style," Cognition 92(3), B1-B12. https:// doi.org/10.1016/j.cognition.2003.10.003

Miščević N. (2018), "Predicates of Personal Taste: Relativism, Contextualism or Pluralism?," Croatian Journal of Philosophy 18(3), 385-401.

Moltmann F. (2010), "Relative Truth and the First Person," Philosophical Studies 150(2), 187-220. https://doi.org/10.1007/s11098-009-9383-9

Moltmann F. (2012), "Two Kinds of First-Person-Oriented Content," Synthese 184(2), 157177. https://doi.org/10.1007/s11229-010-9730-6

Montminy M. (2009), "Contextualism, Relativism and Ordinary Speakers' Judgments," Philosophical Studies 143(3), 341-356. https://doi.org/10.1007/s11098-008-9203-7

Nado J. (2016), “The Intuition Deniers,” Philosophical Studies 173(3), 781-80o. https:// doi.org/10.1007/s11098-015-0519-9

Odrowąż-Sypniewska J. (2013), "Paraconsistent vs. Contextual Solutions to Sorites," Polish Journal of Philosophy 7(2), 21-36. https://doi.org/10.5840/pjphil2013728

Palmira M. (2014), “The Semantic Significance of Faultless Disagreement," Pacific Philosophical Quarterly 96(3), 349-371. https://doi.org/10.1111/papq.12038

Partington A., Duguid A., Taylor C. (2013), Patterns and Meanings in Discourse: Theory and Practice in Corpus-Assisted Discourse Studies (CADS), Amsterdam: Library of Congress. https://doi.org/10.1075/scl.55 
Putnam H. (1975), Mind, Language and Reality. Philosophical Papers, vol. 2, Cambridge: Cambridge University Press. https://doi.org/10.1017/CBO9780511625251

Rose D., Danks D. (2013), "In Defense of a Broad Conception of Experimental Philosophy," Metaphilosophy 44(4), 512-532. https://doi.org/10.1111/meta.12045

Rowley M., Robinson E. J. (2008), "Moral Contextualism and Moral Relativism," The Philosophical Quarterly 58(232), 385-409. https://doi.org/10.1111/j.1467-9213.2007. 543.x

Shieber J. (2012), “A Partial Defense of Intuition on Naturalist Grounds," Synthese 187, 321-341. https://doi.org/10.1007/s11229-010-9864-6

Sinclair J. (2004), Trust the Text: Language, Corpus and Discourse, London: Routledge.

Stojanovic I. (2007), "Talking about Taste: Disagreement, Implicit Arguments, and Relative Truth," Linguistics and Philosophy 30(6), 691-706. https://doi.org/10.1007/s109880o8-9030-5

Stojanovic I. (2012), "Emotional Disagreement: The Role of Semantic Content in the Expression of, and Disagreement Over, Emotional Values," Dialogue: Canadian Philosophical Review 51(1), 99-117. https://doi.org/10.1017/So01221731200025X

Strickland B., Suben A. (2013), "Experimenter Philosophy: The Problem of Experimenter Bias in Experimental Philosophy," Review of Philosophy and Psychology 3(3), 457467. https://doi.org/10.1007/s13164-012-0100-9

Tallant J. (2013), "Intuitions in Physics," Synthese 190, 2959-2980. https://doi.org/ 10.1007/s11229-012-0113-Z

Tallant, J., Andow, J. (2020), "English Language and Philosophy" [in:] The Routledge Handbook of English Language and Digital Humanities, S. Adolphs, D. Knight (eds.), Routledge, 440-455. https://doi.org/10.4324/9781003031758-23

Weatherson B. (2009), "Conditionals and Indexical Relativism," Synthese 166(2), 333-357. https://doi.org/10.1007/s11229-007-9283-5

Weinberg J. M. (2007), "How to Challenge Intuitions Empirically without Risking Skepticism," Midwest Studies in Philosophy 31, 318-43. https://doi.org/10.1111/j.1475-4975. 2007.00157.x

Williamson T. (2007), The Philosophy of Philosophy, Malden, MA: Blackwell Publishing. https://doi.org/10.1002/9780470696675

Wright C. (2007), "New Age Relativism and Epistemic Possibility: The Question of Evidence," Philosophical Issues 17, 262-283. https://doi.org/10.1111/j.1533-6077.2007.00133.x 